\title{
Dua Strategi Misi Mahasiswa Sekolah Teologi di Indonesia Masa Kini
}

\author{
Johana Betris Tumbol \\ Sekolah Tinggi Filsafat Theologia Jaffray Makassar \\ johanabtumbol@gmail.com
}

\begin{abstract}
The purpose of this research is to find a mission strategy that is relevant to the students of the Theology school in Indonesia today. The methodology used is qualitative research on matters related to the library, by first knowing the practical usefulness of the topic to be researched. The author uses a tool that is mapping the research topic. Writers of literature through the Publish or Perish application and collect information about the missions carried out by Theology school students through interviews, then the author uses the results of the literature and interviews and makes a synthesis of the mission strategies of Theology school students so as to produce new findings in the form of conventional mission strategies for returning home missions. as a short-term mission, and a nonconventional mission strategy, namely a mission on social media as a mission strategy for students of theology seminary in Indonesia.
\end{abstract}

Keywords: shot-term mission; the return home mission; social media missions; strategy of mission

\begin{abstract}
Abstrak
Tujuan dari penelitian ini adalah untuk menemukan strategi misi yang relevan dengan mahasiswa sekolah Teologi di Indonesia masa kini. Metodologi yang dilakukan adalah penelitian kualitatif berupa tinjauan pustaka, dengan mengidentifikasi terlebih dahulu topik yang akan diteliti mengenai kebermanfaatannya secara praktis. Penulis menggunakan alat bantu yaitu map a reseach topik. Penulis mengumpulkan literatur-literatur melalui aplikasi Publish or Perish dan mengumpulkan informasi mengenai misi yang dilakukan mahasiswa sekolah teologi melalui wawancara. Kemudian penulis menggunakan hasil tinjauan pustaka dan wawancara tersebut dan membuat sintesis mengenai strategi misi mahasiswa sekolah teologi sehingga menghasilkan temuan baru berupa strategi misi konvensional yaitu misi pulang kampung sebagai misi jangka pendek (short-term mission), dan strategi misi non konvensional yaitu misi di media sosial sebagai strategi misi bagi mahasiswa sekolah teologi di Indonesia.
\end{abstract}

Kata Kunci: misi jangka pendek; misi pulang kampung; misi media sosial, strategi 


\section{Pendahuluan}

Mahasiswa sekolah Teologi diharapkan menjadi pribadi-pribadi unggul dalam kehidupan rohani, dalam keilmuan yang ditekuni, terampil dalam pelayanan, dan memiliki sikap hati yang benar di hadapan Tuhan. Sebagai calon-calon pelayan Tuhan, jemaat, dan masyarakat, mereka dibekali dengan pengetahuan teologi dan pengetahuan yang relevan lainnya sehingga dapat diaplikasikan dalam pelayanan di gereja dan masyarakat. Salah satu pendidikan yang mereka terima adalah pendidikan misi yang biasa dikenal dengan istilah misiologi atau ilmu yang mempelajari seluk-beluk misi. Dalam Kamus Besar Bahasa Indonesia didefinisikan sebagai pengetahuan tentang penyebaran agama. ${ }^{1}$ Mata kuliah misiologi memberikan mahasiswa peluang bukan saja belajar misi di kelas tetapi juga di luar kelas dalam interaksi dengan masyarakat sekitar. Khusus untuk misi Kristen maka mahasiswa sekolah teologi melakukan praktek pewartaan kabar baik dengan menggunakan sarana berbentuk traktat maupun tanpa traktat atau secara lisan. Adanya pandemi covid-19 dan kemajuan teknologi, maka praktek misi Kristen mengalami perubahan yang sangat signifikan baik model maupun keterlibatannya. Walaupun demikian bukan berarti misi pewartaan kabar baik tidak bisa dilakukan.

Awal abad ke-21 dibandingkan dengan abad-abad sebelumnya, banyak penelitian difokuskan kepada misi jangka pendek. Di antaranya yang dilakukan oleh Robert J. Priest and Joseph Paul Priest. Dimana mereka telah mengadakan survey terhadap 5270 siswa dari seminari dan perguruan tinggi Kristen di Amerika tentang partisipasi mereka dalam misi jangka pendek (siapa yang pergi, ke mana mereka pergi, kapan dan untuk berapa lama, berapa biayanya, dengan kelompok ukuran apa mereka bepergian). Untuk meneliti implikasi dari pola-pola ini, cara di mana pembelajaran misiologis dapat dibawa ke dalam hubungan yang lebih konstruktif dengan layanan jangka pendek. ${ }^{2}$ Dari 48 seminari yang telah diteliti, antara 30 dan 70 persen siswa di sebagian besar seminari telah melakukan perjalanan ke luar negeri dalam perjalanan misi jangka pendek. ${ }^{3}$ Dan hal itu dilakukan mereka secara sukarela pada musin liburan musim panas. Namun demikian mereka mengeluarkan biaya yang cukup besar sekitar $\$ 1.001-\$ 3000.4$

Penelitian lain dilakukan oleh Kurt Alan Ver Beek dengan mensurvei 162 peserta misi jangka pendek yang melakukan perjalanan ke Honduras untuk membantu membangun rumah setelah Badai Mitch yang menghancurkan tahun 1998. Beek menemukan bahwa sementara peserta melaporkan bahwa perjalanan mereka telah menghasilkan perubahan signifikan dalam hidup mereka, termasuk pemberian finansial mereka, catatan donasi mereka tidak mencerminkan perbedaan substansial, fakta yang mempertanyakan perubahan positif yang dilaporkan sendiri

1 “KBBI Daring," Kemendikbud, last modified 2016, https://kbbi.kemdikbud.go.id/entri/korupsi.

2 Robert J Priest and Joseph Paul Priest, "'They See Everything, and Understand Nothing' Short-Term Mission and Service Learning," Missiology: An International Review XXXVI, no. I (2008): 5373.

${ }^{3}$ Ibid. 54.

${ }^{4}$ Robert J Priest and Joseph Paul Priest, "'They See Everything, and Understand Nothing' Short-Term Mission and Service Learning," Missiology: An International Review XXXVI, no. 1 (2008): 5373. 57. 
di area lain. ${ }^{5}$ Studi ini juga membandingkan tanggapan lebih dari 30 keluarga Honduras yang memiliki rumah baru yang dibangun untuk mereka oleh kelompok misi jangka pendek Amerika Utara setelah badai dengan tanggapan dari sejumlah keluarga Honduras yang rumahnya dibangun bukan oleh orang Amerika Utara tetapi oleh organisasi Kristen Honduras. Ditemukan bahwa memiliki rumah yang dibangun oleh kelompok misi jangka pendek Amerika Utara versus organisasi Kristen Honduras tampaknya tidak membuat perbedaan bagi pemilik rumah baru, positif atau negatif, meskipun fakta bahwa kelompok misi jangka pendek menghabiskan rata-rata lebih dari $\$ 30.000$ untuk membangun rumah organisasi Kristen lokal bisa membangun dengan $\$ 2000$.

Akhirnya, Kurt Alan Ver Beek mengusulkan agar peserta misi jangka pendek dan penerima Honduras menyerupai percontohan, yang dapat ditekuk dan ditampung di satu tempat selama seminggu atau lebih, tetapi begitu dilepaskan dengan cepat kembali ke keadaan semula. Kurt Alan Ver Beek mengakhiri dengan merenungkan bagaimana "model percontohan" ini menjelaskan fakta bahwa organisasi Kristen lokal memiliki dampak yang jauh lebih besar pada keluarga daripada kelompok misi jangka pendek dan implikasinya untuk meningkatkan dampak misi jangka pendek di masa depan. 6

Dari dua penelitian di atas memperlihatkan bahwa misi jangka pendek keluar negeri membutuhkan biaya yang sangat besar dan belum tentu memberi dampak yang lebih baik dibandingkan dengan misi orang Kristen lokal. Sebab itu ada peluang bagi mahasiswa sekolah Teologi di Indonesia yang memiliki keterbatasan biaya dan bahasa untuk melakukan misi ke luar negeri, bisa melakukan misi jangka pendek dengan cara lain yaitu melalui misi pulang kampung. Selain biaya yang lebih rendah namun dampaknya bisa memberikan pembelajaran penting bagi kelompok mahasiswa yang melakukannya, dan bagi orang-orang dalam konteks yang dituju. Misi jangka pendek ini bersinergi dengan penduduk lokal dan dapat dilanjutkan kepada misi jangka panjang, seperti yang dilakukan oleh misi jangka pendek orang Amerika di Peru. ${ }^{7}$

Adanya perubahan teknologi informasi yang cukup pesat, dan jaringan internet yang sangat mendukung, dan dipercepat oleh adanya pandemi covid-19 telah memberikan peluang juga bagi mahasiswa sekolah Teologi untuk melakukan misi penjangkauan keluar yaitu melalui misi di media sosial. Sehingga mahasiswa punya alternatif lain dalam melakukan misi pada masa kini.

Mengapa dua strategi misi ini menjadi penting bagi mahasiswa sekolah teologi? sebab mahasiswa sekolah teologi adalah bagian dari murid-murid Kristus yang perlu melaksanakan Amanat Agung. Mereka perlu memiliki pengalaman pelayanan misi selama mereka menempuh pendidikan di sekolah teologi. Baik itu misi yang konvensional maupun yang non konvensional. Pada misi konvensional, Siswa dapat mengalami pertumbuhan dalam iman, kehidupan, identitas, dan

${ }^{5}$ Kurt Alan Ver Beek, "The Impact of Short-Term Missions: A Case Study of House Construction in Honduras after Hurricane Mitch," Missiology: An International Review 34, no. 4 (2006): 477-495.

${ }^{6}$ Ibid. 477.

${ }^{7}$ B Hunter Farrell, "From Short-Term Mission to Global Discipleship : A Peruvian Case Study," Missiology: An International Review 4, no. 2 (2013): 163-178. 
kesadaran dunia mereka dari perjalanan misi jangka pendek tersebut. ${ }^{8}$ Selain itu, melakukan perjalanan misi secara signifikan meningkatkan kemungkinan remaja berpartisipasi dalam berbagai bentuk kegiatan sipil, terutama kegiatan berbasis agama dan pekerjaan sukarela. ${ }^{9}$ Sedangkan misi non konvensional melalui misi di media sosial, mereka dapat pengalaman berkomunikasi misi melalui platform digital dan menjangkau orang-orang yang menjadi fokus misinya serta mengembangkan kemampuan membangun tim yang solid melalui pembuatan konten-konten misi.

Jadi tulisan ini bertujuan untuk mendeskripsikan dua strategi misi yaitu yang bersifat konvensional berupa misi pulang kampung dan misi non konvensional berupa misi di media sosial. Adapun perbedaan strategi misi jangka pendek ini dengan beberapa penelitian sebelumnya yaitu penelitian misi jangka pendek sebelumnya berfokus penjangkauan ke luar negeri yang berbiaya besar sedangkan penelitian misi jangka pendek ini berfokus pada misi pulang kampung dan misi di media sosial yang bisa dijangkau secara pendanaan dan fisik oleh mahasiswa teologi di Indonesia.

\section{Metode Penelitian}

Metode penelitian yang digunakan adalah metode penelitian kualitatif. Peneliti mengidentifikasi terlebih dahulu topik yang akan diteliti mengenai kebermanfaatannya secara praktis. ${ }^{10}$ Untuk menemukan novelty, mendapatkan gambaran umum, artikel-artikel penelitian dan mengidentifikasi konsep yang relevan, penulis menggunakan alat bantu yaitu map a reseach topic. Penulis mengumpulkan literatur-literatur yang relevan berupa hasil-hasil penelitian sebelumnya yang berkaitan dengan: misi dalam Alkitab, strategi misi, misi jangka pendek (short-term mission) misi kontekstual, misi di media sosial, melalui aplikasi Publish or Perish. Kemudian penulis mengumpulkan informasi mengenai misi yang dilakukan mahasiswa sekolah teologi melalui wawancara pada mahasiswa yang mengikuti misi jangka pendek berupa misi pulang kampung, membuat tinjauan terhadap literatur-literatur dan informasi tersebut untuk membuat kerangka kerja yang sistematis untuk mempertegas pentingnya penelitian ini. Penulis menggunakan hasil tinjauan pustaka dan wawancara tersebut dan membuat sintesis mengenai strategi misi mahasiswa sekolah Teologi sehingga menghasilkan temuan baru bahwa strategi misi konvensional berupa misi pulang kampung sebagai misi jangka pendek (short-term mission), dan misi non konvensional berupa misi di media sosial sebagai strategi misi bagi mahasiswa sekolah teologi di Indonesia yang dapat diimplementasikan pada masa kini.

8 Terence D Linhart, "Planting Seeds : The Curricular Hope of Short Term Mission Experiences in Youth Ministry," Christian Education Journal 2, no. 2 (2005): 256-272.

${ }^{9}$ Kraig Beyerlein, Jenny Trinitapoli, and Gary Adler, "The Effect of Religious Short-Term Mission Trips on Youth Civic Engagement," Journal for the Scientific Study of Religion 50, no. 4 (2011): 780-795.

10 John W. Creswell, Research Design: Qualitative, Quantitative, and Mixed Methods Approaches (Thousand Oaks: Sage Publication, Inc, 2009). 23. 


\section{Hasil dan Pembahasan \\ Dasar Misi}

Sebelum membahas misi pulang kampung, perlu melihat dasar misi di Alkitab. Menurut John R.W. Stott, tingkat komitmen gereja terhadap penginjilan dunia berbanding lurus dengan tingkat keyakinannya terhadap otoritas Alkitab. Hal ini berarti semakin tinggi tingkat keyakinan terhadap otoritas Alkitab maka semakin tinggi komitmen gereja terhadap penginjilan.

Menurutnya Stott, ada empat alasan mengapa Alkitab tidak terpisahkan dari penginjilan dunia yaitu: pertama, Alkitab memberi kita mandat untuk penginjilan dunia. Kedua, Alkitab memberi kita berita untuk penginjilan dunia. Ketiga, Alkitab memberi kita model untuk penginjilan dunia. Keempat, Alkitab memberi kita kuasa untuk penginjilan dunia. Tapi apakah Alkitab dapat dipercaya sebagai Firman Allah? Bartholomeus D. Nainggolan mendiskusikan pertanyaan tersebut dalam tulisannya dan dia memberikan bukti-bukti baik internal maupun eksternal bahwa Alkitab memang diilhamkan Allah jadi dapat dipercaya. Craig L. Blomberg setelah ia melakukan penelitian yang mendalam mengenai pertanyaan kontemporer ini, sampailah ia pada kesimpulan bahwa kita masih bisa dengan sepenuh hati memercayai Alkitab di abad 21, bahkan setelah jujur melibatkan pertanyaanpertanyaan kontemporer.

Misi Allah atau Missio Dei tidak dimulai dari Amanat Agung tapi jauh sebelum Amanat Agung yakni nampak saat manusia pertama kali jatuh dalam dosa. Tuhan mencari manusia yang telah jatuh ke dalam dosa. Pergerakan misi Allah berlanjut pada Israel sebagai suatu bangsa ketika Ia membawa mereka keluar dari tempat perbudakan di Mesir menuju ke tanah perjanjian yaitu Kanaan. Kemudian misi Allah disampaikan melalui para nabi-nabi, dan sampai pada Kristus. Missio Dei merupakan Allah yang berinkarnasi menjadi manusia. Allah yang masuk dalam budaya, tinggal dalam masyarakat yang berbudaya Yahudi, dan yang dianggap sudah memporakporandakan kepercayaan yang sudah membudaya dalam hidup mereka. Menurut Richard Niebuhr, kelompok yang mendukung pemikiran tersebut menganggap keyakinan dan budaya yang dihidupi sudah dicemari dosa.

Hal ini bertolak belakang dengan Yesus yang datang membawa damai sejahtera dan bukan pertentangan. G. J. Baan mengingatkan bahwa semua orang telah berdosa, tidak ada satupun yang mencari Allah. Persamaan semua orang dihadapan Allah adalah jahat dan berdosa. Namun orang-orang yang berdosa ini oleh karena kehendak dan kedaulatan Allah, sebagian dari mereka diselamatkan. Inilah yang Allah kerjakan melalui inkarnasi yaitu menyelamatkan manusia yang berdosa agar mereka memiliki hidup yang damai dan sejahtera. Misi ini telah dimandatkan oleh Yesus kepada murid-murid-Nya (Mat. 28:19-20), dan saat ini kepada semua orang yang percaya untuk menjadi saksi mulai dari Yerusalem, Yudea, Samaria sampai ke ujung bumi (Kis. 1: 8). Namun banyak orang bertanya: haruskah saya pergi untuk misi? Siapakah yang harus pergi? Apakah Allah memanggilku? Apa itu panggilan misi? Cara untuk menemukan kehendak Allah menurut M. David Sills, adalah dengan menjadi begitu dekat dengan-Nya sehingga jantung Anda seirama dengan detak jantung Allah sendiri. 


\section{Misi Lintas Budaya di Indonesia}

Misi sangat penting untuk dijalankan tetapi budaya juga penting untuk diketahui sebelum seseorang atau sekelompok orang menjalankan misi. Kebudayaan bisa menjadi jembatan dalam mengerjakan misi. Misi perlu didasarkan pada fondasi yang kokoh, sebelum berjumpa dengan kebudayaan. ${ }^{11}$ Misi lintas budaya merupakan sebuah kegiatan yang dilakukan untuk menjangkau orang-orang lain di luar budaya sendiri. Contohnya adalah strategi penginjilan Yesus di Injil Markus. Dengan cara mengerti budaya lokal, memakai media yang tersedia dalam budaya, memaksimalkan potensi yang ada, dan membuat terobosan. ${ }^{12}$ Dalam melaksanakan misi lintas budaya Rasul Paulus dalam 1 Tesalonika 2:6-8, mengungkapkan bahwa Rasul Paulus tidak memaksakan peraturan-peraturan gaya hidup orang Yahudi kepada orang bukan Yahudi yang sudah percaya kepada Yesus. Apalagi Paulus melihat pentingnya membagikan hidupnya, bukan hanya berita Injil. ${ }^{13}$

Indonesia merupakan sebuah negara ke-4 terbesar di dunia dengan jumlah penduduk 270,20 juta jiwa berdasarkan Sensus tahun 2020.14 Dari data yang dikeluarkan oleh Joshua Project di Indonesia, ada 789 kelompok orang dan ada 235 kelompok masyarakat yang belum terjangkau. Agama terbesar adalah Islam 82,3\%, penganut Kristen 12,7\%, 3,15\% Injili dan tingkat pertumbuhan tahunan Injili 2,8\%. Kelompok orang ini dapat dikatakan kelompok suku bangsa yang berbeda bahasa dan budaya.

Melalui data ini kita mengetahui bahwa masih cukup banyak kelompok orang yang perlu dijangkau. Hal ini nyata dalam kehidupan kita sehari-hari dimana teman sekolah, teman kantor, dan tetangga kita adalah orang-orang yang belum terjangkau. Bahkan ketika dalam keluarga kita terjadi pernikahan lintas agama, maka akan ada anggota-anggota keluarga kita yang belum pengenal Yesus dan percaya kepadaNya. Hal ini banyak terjadi di Indonesia yang memiliki pluralitas agama. Berikut ini gambaran kelompok orang di Indoensia seperti yang dipaparkan oleh Joshua project.

11 Firman Panjaitan and Hendro Siburian, "Misi Kristologi Dalam Konteks Kebudayaan," Logia: Jurnal Teologi Pentakosta Vol 1, no. 1 (2020): 42-59. 42.

12 H Harming and K Katarina, "Strategi Pelayanan Lintas Budaya Berdasarkan Markus 4:134," Evangelikal: Jurnal Teologi Injili dan Pembinaan Warga Jemaat 3, no. 1 (2019): 113.

13 Sherwood G. Lingenfelter and Marvin K. Mayers, Menggeluti Misi Lintas-Budaya: Meniru Kristus Mengatasi Perbedaan (Jakarta: Yayasan Komunikasi Bina Kasih, 2008). 88.

14 "Hasil Sensus Penduduk Tahun 2020," Badan Pusat Statistik, last modified 2021, accessed June 13, 2021, https://www.bps.go.id/. 


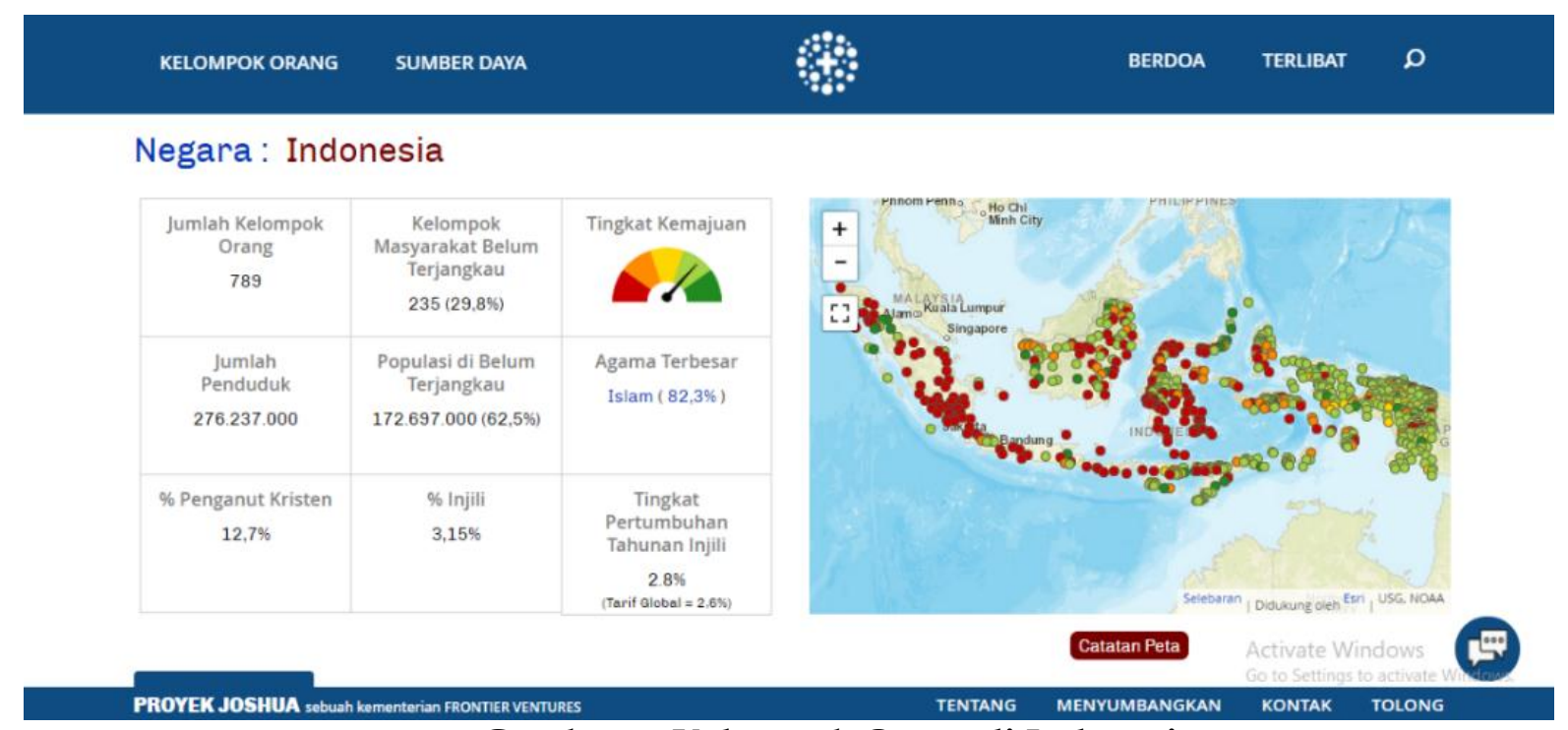

Gambaran Kelompok Orang di Indonesia ${ }^{15}$

Banyak faktor yang mempengaruhi keberhasilan dari suatu misi lintas budaya. Selain dari kebergantungan pada Kuasa Roh Kudus maka perlu hikmat dan strategi khusus dengan melibatkan ilmu pengetahuan yang ada. Menurut David J. Hesselgrave, ilmu pengetahuan harus mengambil tempatnya sebagai pelayan keyakinan, sebab pertobatan pada pokoknya adalah karya Roh Kudus. ${ }^{16}$ Pengetahuan yang dimaksud berhubungan dengan teori-teori komunikasi dan misi, komunikasi dan kultur, pandangan-pandangan dunia, cara memahami dunia, proses-proses kognitif, cara-cara berpikir, bentuk-bentuk linguistik, cara-cara mengekspresikan gagasan, pola-pola perilaku, cara-cara bertindak, struktur-struktur sosial, cara-cara mempengaruhi, pengaruh media, cara-cara menyalurkan berita, dan sumber-sumber motivasional, cara-cara memutuskan. ${ }^{17}$ Hal-hal itu perlu menjadi pertimbangan agar sasaran misi tercapai yaitu menjangkau suku-suku bangsa agar supremasi Kristus ada di antara suku-suku bangsa di dunia. ${ }^{18}$

\section{Strategi Misi Konvensional: Misi Pulang Kampung}

Frasa "pulang kampung" menurut Kamus Besar Bahasa Indonesia, berarti pulang ke kampung halaman. ${ }^{19}$ Sedangkan kata yang sinonim dengan kata itu "mudik" yang berarti berlayar, pergi ke udik (hulu sungai, pedalaman). ${ }^{20}$ Jadi pulang kampung berarti orang meninggalkan tempat tinggalnya dimana dia telah tinggal, sekolah, dan bekerja sebagai perantau dan kembali ke tempat asalnya

\footnotetext{
15 “Kelompok Orang: Indonesia," The Joshua Project, last modified 2021, accessed June 13, 2021, joshuaproject.net.

${ }^{16}$ David J. Hesselgrave, Communicating Christ Cross-Culturally, Edisi Kedua. (Malang: Literatur SAAT, 2005). 627.

17 Ilmu pengetahuan ini disimpulkan dari keseluruhan uraian dalam buku Communicating Christ Cross-Culturally yang ditulis oleh David J. Hesselgrave.

18 John Piper, Jadikan Sekalian Bangsa Bersukacita: Supremasi Allah Dalam Misi, ed. Doreen Widjaya (Bandung: Lembaga Literatur Baptis, 2003). 339.

${ }^{19}$ KBBI, "Kamus Besar Bahasa Indonesia," Kbbi.Web.Id, last modified 2021, https://kbbi.kemdikbud.go.id/entri/Pulang kampung.

${ }^{20}$ Ibid.
} 
dimana dia dibesarkan, kepada keluarga, sahabat, kerabat, dan masyarakat setempat.

Istilah ini digunakan oleh penulis untuk memaknai perjalanan misi yang sesuai dengan konteks budaya Indonesia. Frasa "pulang kampung" adalah sebuah istilah yang digunakan masyarakat ketika memasuki musim liburan oleh individuindividu dan keluarga-keluarga. Biasanya dihubungkan dengan liburan berkenaan dengan hari raya keagamaan. Pulang kampung sudah menjadi budaya, ketika banyak masyarakat desa bermingrasi ke kota untuk mencari pekerjaan dan melanjutkan pendidikannya. Misi "pulang kampung" merupakan strategi yang dibuat untuk menghalau beberapa hambatan yang biasa terjadi dalam misi. Misalnya kebutaan budaya, maka kita perlu berinkarnasi di dalam budaya dan kehidupan orang-orang yang dilayani. Kita harus menjadi murid dan membiarkan mereka mengajar kita sebelum kita bisa mengajar mereka. ${ }^{21} \mathrm{Hal}$ ini memakan waktu yang cukup lama untuk mempelajari kebudayaan baru. Bukan hanya waktu yang banyak tetapi juga dana yang besar. Misi pulang kampung dikategorikan sebagai misi jangka pendek (short-term mission). Priest mendefinisikannya dalam waktu kurang dari dua Minggu atau maksimum dua minggu. ${ }^{22}$ Sebab hal tersebut dilakukan dalam musim liburan sekolah atau liburan kuliah pada bulan Januari atau Juli.

Dalam konteks misi di Indonesia, selama abad-abad 18-20, sudah banyak badan-badan misi internasional yang mengirim misionari-misionari ke Indonesia untuk menjangkau susu-suku bangsa yang mendiami kepulauan Nusantara. Di akhir abad ke-20 beberapa Lembaga misi turut terlibat dalam pelayanan di Indonesia seperti Christian Mission Alliance (CMA), ${ }^{23}$ Service in Mission (SIM), ${ }^{24}$ Youth With A Mission (YWAM) ${ }^{25}$ dan lain-lain.

Memasuki abad ke-21, tumbuh kemandirian dalam pengutusan-pengutusan misi dari penduduk lokal yang menjangkau suku-suku bangsa sendiri maupun menjangkau suku-suku bangsa lain. Kemandirian ini bukan berarti meniadakan kebutuhan akan para misionari dari luar negeri tapi paling tidak, mereka dapat melihat buah-buah dari pelayanan mereka dengan mengirim kembali orang-orang lokal yang sudah mereka muridkan baik di sekolah-sekolah Teologi maupun melalui Gereja-gereja dan Lembaga-lembaga misi. Seperti yang dilakukan Sekolah-sekolah Teologi di Indonesia seperti STFT Jaffray Makassar yang mengutus kembali para

21.

${ }^{21}$ Lingenfelter and Mayers, Menggeluti Misi Lintas-Budaya: Meniru Kristus Mengatasi Perbedaan.

22 Priest and Priest, “'They See Everything, and Understand Nothing' Short-Term Mission and Service Learning." 56.

23 “The Christian Missionary Alliance (CMA)," last modified 2021, accessed June 12, 2021, https://cmalliance.org/about/.

24 "Serving in Mission (SIM)," SIM adalah singkatan dari Melayani Dalam Misi. Di seluruh dunia SIM memiliki lebih dari 4000 pekerja aktif saat ini lebih dari 70 Negara yang melayani hampir di setiap benua kecuali Antartika. last modified 2021, accessed June 12, 2021, https:/ / sim.org.nz/. "Youth With A Mission," Youth With A Mission (YWAM) didirikan tahun 1960, sekarang sudah menjadi salah satu pelayanan Kristen terbesar secara Internasional dan interdenominasi. Yayasan YWAM memiliki 12.000 relawan yang ada di 700 lokasi di 135 negara. Sebagai tambahan setiap tahun puluhan ribu orang dari banyak negara terlibat dalam pelayanan misi jangka pendek. last modified 2021, accessed June 12, 2021, https:/ / ywam.org/. 
mahasiswanya untuk melakukan misi ke daerah-daerah asalnya. Para mahasiswa ini yang berasal dari beberapa daerah berkumpul membentuk tim yang akan pergi ke salah satu daerah misi yang sudah disepakati dan didoakan. Mahasiswa dan dosen pendamping mempelajari bahasa dan budaya daerah tersebut melalui mahasiswa yang berasal dari daerah target misi. Bagi mahasiswa yang bukan berasal dari daerah tersebut, ini merupakan misi lintas budaya, sedangkan bagi mahasiswa yang berasal dari daerah tersebut, ini merupakan misi "pulang kampung." Menjangkau masyarakat yang belum terjangkau di kampung halaman dan sekitarnya. Seperti kisah penginjilan dalam Alkitab oleh Yesus dan murid-muridnya. Mereka menginjil di daerah Yudea, Galilea, dan Samaria (lihat kitab-kitab Injil) yang masih satu bahasa dan memiliki kemiripan budaya dengan mereka. Pendekatan yang dilakukan oleh Yesus adalah menyembuhkan orang sakit, mengusir setan-setan, membangkitkan orang mati, mengajar tentang Kerajaan Allah dan memuridkan. Sebab itu misi yang perlu dilakukan oleh misionaris lokal (mahasiswa) ketika mereka sudah dilatih untuk melakukan misi penjangkauan, yaitu misi "pulang kampung." Menjangkau kelompok orang yang belum terjangkau dapat dilakukan dengan berbagai cara seperti: melalui misi kemanusiaan: pengobatan, pendidikan. Misi sosial: pelatihan membuat air bersih, pertanian, mengembangkan produk lokal, ceramah narkoba, pelatihan SDM. Misi spiritual: pemberitaan Kerajaan Allah, pengusiran setan-setan, dan pemuridan.

Misi yang dilakukan oleh Tim Misi Sulut (mahasiswa yang tergabung dalam persekutuan mahasiswa Sulawesi Utara) pada bulan Juni 2021 ke daerah Ampana Sulawesi Tengah, telah dilakukan selama empat belas hari sudah termasuk perjalanan pulang pergi dengan kendaraan Bus. Lokasi ini dipilih setelah mempertimbangkan bahasa, dan kebudayaan, yang mirip dengan Bahasa dan budaya masyarakat Sulawesi Utara. Tim juga mempertimbangkan kebutuhan masyarakat lokal yang dituju dan ketersediaan penduduk lokal untuk menjadi tempat transit. Mereka melakukan pelayanan kepada jemaat di kota Ampana tetapi juga melakukan pelayanan ke daerah hutan dengan menempuh perjalanan kaki selama 4 jam melewati 2 sungai besar. Pelayanan misi jangka pendek ini merupakan pelayanan misi follow up dari pelayanan misi sebelumnya yang sudah dilakukan oleh Tim Misi mahasiswa Angkatan 2016 pada tahun 2019 yang lalu.

\section{Kegiatan Misi}

Kegiatan misi yang dilakukan di lokasi pelayanan didasarkan pada kebutuhan masyarakat lokal. Pelayanan yang bersifat sosial seperti melatih ketrampilan guru-guru sekolah Minggu di gereja untuk membuat alat peraga yang dapat digunakan dalam mengajar murid-muridnya. Tim misi melatih masyarakat untuk membuat kerajinan tangan yang bernilai ekonomis seperti membuat boneka dari kertas dan pigura dari stik es krim. Bahan bakunya mudah ditemukan di daerah tersebut. Pelayanan berupa seminar musik dan pelatihan musik kepada pemudapemudi di gereja, sebab gereja memiliki alat musik yang lengkap tetapi tidak memiliki pemain musik, hanya menggunakan keyboard tunggal. Tim misi juga melakukan pelayanan langsung kepada anak-anak dengan pendekatan bercerita, panggung boneka, gerak dan lagu, juga pelayanan doa dan perkunjungan kepada 
anak-anak yang sakit. ${ }^{26}$ Pelayanan misi ke daerah pedalaman adalah pemberitaan kabar baik dalam bentuk ibadah kebaktian kebangunan rohani dan perkunjungan dan doa ke pondok-pondok masyarakat di sekitar hutan tersebut. Mahasiswa dan dosen pembimbing dalam misi pulang kampung ini berdiskusi mengenai kepercayaan masyarakat setempat dan mendapat informasi penyebab masyarakat tersebut sering berpindah-pindah tempat tinggal. Tim misi memberikan pencerahan kepada masyarakat setempat dan berusaha untuk meyakinkan mereka mengenai keuntungan jika mereka tetap tinggal menetap di suatu wilayah. ${ }^{27}$

\section{Keuntungan Misi "Pulang Kampung"}

Misi pulang kampung sudah dilakukan oleh STFT Jaffray Makassar setelah terbentuk persekutuan-persekutuan daerah di kampus. Meskipun Yesus berkata bahwa seorang nabi dihormati di mana-mana kecuali di tempat asalnya sendiri dan di rumahnya (lih. Mark. 13:57), tetapi ini dalam konteks yang berbeda. Sebab selama beberapa tahun STFT Jaffray Makassar mengirim misi pulang kampung, belum pernah ada kasus yang ditolak. ${ }^{28}$ Ada beberapa keuntungan ketika melakukan misi pulang kampung oleh mahasiswa dan dosen; pertama, kegagalan misi karena kendala komunikasi menjadi minim. Komunikasi itu fundamental bagi manusia. ${ }^{29}$ Karena itu kendala komunikasi ini perlu diminimalisir. Kedua, mahasiswa yang diutus dan masyarakat memiliki budaya yang sama sehingga penyesuaian budaya tidak perlu memerlukan waktu bertahun-tahun. Sebab Misi yang tanpa memedulikan kebudayaan di masyarakat banyak menemui kegagalan. ${ }^{30}$ Meskipun demikian ada yang dinamakan kebudayaan pribadi dan ada budaya yang dimiliki bersama. ${ }^{31}$ Budaya yang dimiliki bersama ini menjadi modal dalam bermisi. Ketiga, hemat biaya atau dana sebab akomodasi, konsumsi, transportasi, menjadi lebih murah sebab bisa tinggal di rumah keluarga atau kerabat. Sebab salah satu faktor yang dibutuhkan oleh seorang misionaris adalah dukungan dana. ${ }^{32}$ Itulah beberapa keuntungan dari misi "pulang kampung." Hal yang penting juga untuk dilakukan adalah kemitraan dalam bermisi.

\section{Bermitra Dalam Misi}

Dasar alkitabiah bermitra dalam misi telah diterapkan sejak Allah sendiri merencanakan keselamatan bagi dunia. Allah Tritunggal bersama-sama

\footnotetext{
${ }^{26}$ Penulis, Wawancara Dengan Jeanet Memah Seorang Mahasiswa Peserta Mission Trip Ke Ampana (Makassar, 2021).

27 Penulis, Wawancara Dengan Andrew Suplig, M.Th Sebagai Dosen Pembimbing Tim Misi Ke Ampana (Makassar, 2021).

28 "Laporan Misi" (Makassar: Sekolah Tinggi Filsafat Jaffray, 2020). Dari laporan mahasiswa yang mengikuti misi yang disampaikan dalam bentuk pertanggungjawaban di pertemuan Kapel menyebutkan bahwa mereka sangat diterima dan melalui pelayanan mereka ada orang lokal yang beragama suku menerima Yesus dan dibaptis.

${ }^{29}$ Hesselgrave, Communicating Christ Cross-Culturally. 27.

${ }^{30}$ Panjaitan and Siburian, "Misi Kristologi Dalam Konteks Kebudayaan." $17-21$.

${ }^{31}$ Lingenfelter and Mayers, Menggeluti Misi Lintas-Budaya: Meniru Kristus Mengatasi Perbedaan.

32 Purnawan Tenibemas, “Andil Kita Dalam Misi Masa Kini,” Pengarah: Jurnal Teologi Kristen 1, no. 1 (2019): 23-36. 34.
} 
melaksanakan karya penyelamatan bagi dunia. Ria Pasaribu dalam bab 13 buku Jemaat Misioner telah mendiskusikan hal ini. ${ }^{33}$ Contohnya dapat kita lihat pada surat Paulus kepada jemaat di Efesus pasal 1 sebagai berikut: Pertama, Allah Bapa dalam Yesus Kristus mengaruniakan segala berkat rohani di dalam Surga (ay 3). Kedua, Kristus yang melakukan penebusan dosa di kayu salib (ay 7). Ketiga, Roh Kudus memeteraikan orang percaya, sebagai jaminan bagiannya sampai keselamatan yang dijanjikan utuh sepenuhnya (ay 13-14). Bahkan Roh Kudus memberi kuasa kepada Gereja untuk bersaksi. Tanpa kuasa dari Roh Kudus, tidak mungkin gereja bisa bersaksi. ${ }^{34}$ Dari sini kita melihat Allah Tritunggal melaksanakan kemitraan yang indah dan sempurna bagi terwujudnya gereja Tuhan di bumi.

Selanjutnya kemitraan dilanjutkan oleh Roh Kudus, gereja, dan misionaris yang diutus. Kerjasama ini berlangsung dari waktu ke waktu dalam pelayanan Paulus dengan jemaat lainnya. Seperti jemaat Filipi. Paulus menulis tentang persekutuan mereka "dalam berita Injil mulai hari pertama sampai sekarang ini." (Flp 1:5). Eudonia dan Sintikhe telah berjuang dengan Paulus dalam pemberitaaan Injil (Flp 4:2). Setelah mereka mendengarkan Injil dan dibina oleh Paulus, jemaat Filipi berkali-kali mendukung Paulus dalam pekabaran Injil ke tempat-tempat lainnya, baik dengan mengirimkan bantuan kepadanya maupun dengan mengutus Epafroditus untuk melayani kebutuhannya (Flp 2:25; 4:15-18). Jadi kemitraan itu sangat penting dalam bermisi. Apalagi dalam misi lintas budaya di dunia pasca modern. Seperti penelitian yang dilakukan oleh B. D. Nainggolan mengenai tafsiran Kisah Para Rasul 1:8 dan implementasinya dalam kegiatan misi gereja lintas budaya. ${ }^{35}$ Gereja memberikan dukungan bukan hanya dana tapi pendidikan dan ketrampilan kepada gereja-gereja di daerah yang sulit mendapatkan akses dalam menyelesaikan pelayanan misi mereka.

Gereja-gereja juga perlu bermitra dengan sekolah-sekolah teologi dan Lembaga-lembaga misi dalam memberikan pendidikan dan pelatihan kepada jemaat-jemaat yang terpanggil dalam ladang misi. Seperti mempersiapkan jemaatjemaat untuk mengikuti studi misi di kampus atau sekolah Teologi dengan biaya dari gereja sebagai gereja pengutus, memberikan kesempatan kepada mahasiswamahasiswa mengadakan Praktek Kerja Lapangan (PKL) di gereja-gereja dan lembaga-lembaga misi, gereja bermitra dengan Lembaga-lembaga misi seperti Lembaga Pelayanan Mahasiswa Indonesia (LPMI), EE Center, ${ }^{36}$ YWAM, $^{37}$ dan beberapa lembaga misi lainnya dalam memberikan pelatihan penginjilan pribadi, dan lain sebagainya. Secara global, ada gerakan menuju kolaborasi yang lebih besar di antara lembaga, gereja, dan organisasi yang berpikiran misi lainnya. Tren tersebut

${ }^{33}$ Ria Pasaribu, Komunitas Yang Bermitra Dalam Misi (Jakarta: Yayasan Komunikasi Bina Kasih, 2011). 456.

${ }^{34}$ Andrew Brake, Menjalankan Misi Bersama Yesus: Pesan-Pesan Bagi Gereja Dari Kisah Para Rasul (Bandung: Kalam Hidup, 2016). 4.

35 Bartholomeus Diaz Nainggolan, "Interpretation of Acts 1:8 and Its Implementation in CrossCultural Gospel Mission," Jurnal Koinonia 10, no. 2 (2018): 16-18. 31.

36 "Share It," EE Center Indonesia, last modified 2021, accessed June 15, 2021, https://eeindonesia.org/.

37 "Youth With A Mission." 
merupakan hasil dari upaya untuk memperluas dampak Injil dengan membangun kekuatan sumber daya bersama, idealnya melalui komitmen untuk tujuan bersama. ${ }^{38}$

\section{Strategi Misi Non Konvensional: Misi di Media Sosial}

Yesus selama 3,5 tahun misi-Nya di dunia, sering menggunakan media untuk menjangkau orang-orang di berbagai tempat agar mereka mendengar berita tentang Kerajaan Allah. Seperti berjalan kaki, menggunakan perahu, menggunakan hewan dan lainnya. Yesus dan para murid-Nya berinteraksi dengan komunitas masyarakat yang mereka jumpai secara tatap muka. Dalam era kemajuan teknologi informasi dan komunikasi saat ini, masyarakat bukan hanya berinteraksi secara nyata dalam perjumpaan sehari-hari melalui tatap muka tetapi juga telah bermigrasi dengan berinteraksi menggunakan media sosial dalam jaringan internet dengan tatap layar.

Media sosial adalah suatu aplikasi berbasis internet yang memungkinkan penggunanya untuk berinteraksi satu dengan yang lain, melaluinya para pengguna menciptakan, saling bertukar, dan atau berbagi konten informasi. ${ }^{39}$ Dalam era media sosial ini semua orang dapat terhubung dan berkomunikasi menggunakan smartphone, notebook, atau laptop. Inilah yang kita kenal dengan era revolusi Industri 4.0 yang berakar pada kecerdasan buatan (artifisial intelligence). Hal ini menjadikan masyarakat terhubung (connecting society) melalui media sosial. Berbagai macam komunitas tercipta dan berkumpul di berbagai platform media sosial. Informasi menjadi lebih mudah diperoleh. Bahkan informasi sangat berlimpah dan membuat kebisingan di media sosial. Inilah dunia baru yang mengubah tatanan sosial masyarakat. Dimana orang jauh menjadi dekat sedangkan orang dekat sudah menjadi jauh.

Data survei Kominfo tentang penggunaan Teknologi Informasi dan Komunikasi (TIK) tahun $2017^{40}$ kepada 6246 responden menyebutkan bahwa masyarakat Indonesia $66,31 \%$ atau lebih dari 50\% sudah memiliki Smartphone. Kemudian data yang lain mengenai penggunaan media sosial yang disurvey kepada 3934 responden menunjukkan bahwa ada $92,82 \%$ responden menggunakan media sosial, dan hanya 7,18\% yang tidak menggunakan media sosial. Sedangkan tujuan menggunakan smartphone saat terhubung internet paling tinggi adalah komunikasi $93,46 \%$, diikuti hiburan $65,29 \%$, browsing $76,88 \%$, belajar $27,51 \%$, dan bekerja $25,70 \%$. Dari data tersebut kita memeroleh informasi bahwa penggunaan smartphone untuk komunikasi melalui media sosial sangat tinggi. Ini menjadi peluang bagi usaha komunikasi misi Allah melalui media sosial.

\section{Komunikasi Misi}

Misi tidak pernah lepas dari komunikasi. Menurut Donald K. Smith, Komunikasi adalah proses untuk menciptakan perubahan di mana dua pihak atau

\footnotetext{
${ }^{38}$ Nainggolan, "Interpretation of Acts 1:8 and Its Implementation in Cross-Cultural Gospel Mission."

${ }^{39}$ Kominfo, "Media Sosial," n.d.

${ }^{40}$ Kominfo: Survey Penggunaan TIK Serta Implikasinya Terhadap Aspek Sosial Budaya Masyarakat (Jakarta, 2017).
} 
lebih terlibat. ${ }^{41}$ Perubahan ini merupakan peluang yang diciptakan melalui komunikasi. Menurut Quentin J. Schultze, komunikasi memampukan kita untuk turut menciptakan komunitas yang memberi hidup. Dimana Allah adalah pusat komunikasi kita, maka kita akan turut menciptakan komunitas shalom yang damai dan adil. ${ }^{42}$ Jadi melalui misi di media sosial diharapkan tercipta komunitas baru yang memberi hidup yang damai bagi lingkungannya.

Komunikasi dan budaya media sosial menjadi perhatian. Budaya dan komunikasi berinteraksi secara erat dan dinamis. Inti budaya adalah komunikasi, karena budaya muncul melalui komunikasi. Akan tetapi pada gilirannya budaya yang tercipta pun mempengaruhi cara berkomunikasi anggota budaya bersangkutan. ${ }^{43}$ Media sosial memiliki budayanya sendiri, karena itu penting untuk mempelajari budaya yang terbentuk dalam komunikasi di media sosial. Pertama, yang mengakses media sosial tidak dibatasi umur, jenis kelamin, budaya, agama, suku bangsa, ras, tingkat pendidikan, tingkat ekonomi dan pilihan politik, Semua melebur menjadi satu di media sosial. Hal ini bisa dilihat sebagai kesempatan yang baik untuk bisa menjangkau banyak segmentasi kelompok untuk mendengar Injil tapi juga bisa dipandang sulit untuk mendisain komunikasi misi yang tepat sasaran. Kedua, pergesekan berbagai budaya di media sosial dapat menciptakan budaya baru yang positif dan negative. Positif ketika tercipta budaya saling menghargai perbedaan pendapat satu dengan yang lain, saling menerima dan mendukung pada hal-hal yang positif, serta budaya yang menjunjung etika dan norma-norma sosial yang berlaku dalam masyarakat. Sedangkan budaya baru yang negative adalah budaya membenci (haters), bullying, menyukai hoaks, kekerasan, permisif, dan lainlain. Sebab itu komunikasi misi diharapkan menjadi pembawa shalom dalam interaksi di media sosial.

\section{Beberapa Platform Media Sosial Untuk Misi}

Ada beberapa platform yang biasa digunakan oleh masyarakat Indonesia untuk terhubung dan berinteraksi satu sama lain. Contohnya: Whatsapp, Twitter, Facebook, Instagram, dan Youtube. Platform yang paling banyak dipakai menurut survey yang dilakukan GlobalWebIndex dalam databoks adalah Youtube kemudian Whatsapp, Instagram, dan Twitter. Sedangkan yang paling lama digunakan adalah Whatsapp menurut App Annie dalam Databoks. ${ }^{44}$

Misi melalui Yotube, adalah misi dengan konten video atau siaran langsung (live). Konten bisa berupa penginjilan, khotbah, pengajaran, atau pemuridan, ibadah misi, KKR Misi, diskusi misi, kesaksian, film, lagu-lagu, dan lain-lain.

Misi melalui Instagram, adalah misi dengan konten dalam tulisan, disain grafis, foto, video singkat, dan story. Konten bisa berupa kata-kata penginjilan,

${ }^{41}$ Donald K. Smith, Creating Understanding: Buku Panduan Komunikasi Kristen Lintas Budaya (Jogyakarta: Penerbit ANDI, 2014).

${ }^{42}$ Quentin J. Schultze, Communicating for Life: Christian Stewardship in Community and Media (Malang: Literatur SAAT, 2004). 15.

${ }^{43}$ Deddy Mulyana, Komunikasi Efektif: Suatu Pendekatan Lintas Budaya (Bandung: PT. Remaja Rosdakarya, 2005). 14.

44 "Pengguna Media Sosial," Databoks, last modified 2021, accessed June 16, 2021, https:// databoks.katadata.co.id/tags/pengguna-media-sosial. 
Firman Tuhan, hikmat, penguatan, dan lain-lain. Misi melalui Facebook, hampir sama dengan Instagram sebab Instagram bisa dihubungkan dengan Facebook. Update status yang berisi tulisan, foto, video, kesaksian dapat dilakukan melalui platform ini. Update story yang bisa tayang setiap hari bisa menjadi sarana untuk menjangkau para followers dan mendapat respon dari mereka. Whatsapp dan Twitter, bisa juga diisi dengan berbagai macam konten misi sebab kedua plaform ini terhubung dengan individu atau dalam komunitas group (Whatsapp) dan memiliki pengikut (Twitter).

Dari penelitian yang dilakukan oleh Camerling, dkk., mengenai tindakan misi gereja lewat media digital di era Industri 4.0 memberikan hasil bahwa strategi dalam mengkomunikasikan pesan Injil dapat dilakukan melalui khotbah live streaming, rekaman video khotbah, update status di Facebook dan juga Instagram. ${ }^{45}$ Selain itu, ada lagi strategi yang lain dalam bentuk apologetika di aplikasi Discord bagi komunitas para pemain game Among Us di Indonesia.46 Semua kegiatan misi yang dilakukan melalui beberapa platform media sosial yang ada membutuhkan tim yang solid agar misi tersebut dapat dilakukan secara berkelanjutan. Baik dalam bentuk penginjilan maupun pemuridan atau pelipatgandaan.

Ketika membagun misi di media sosial maka perlu memiliki tim yang solid. Seperti kesimpulan yang dibuat oleh Setiyanti dalam tulisannya mengenai membangun kerja sama tim, bahwa tidak ada organisasi atau perusahaan yang berhasil karena "superman" tapi karena "superteam." 47 Tim yang memiliki hati yang mengasihi Tuhan dan terpanggil dalam misi di media sosial. Kerja bersama tim akan membuat pekerjaan yang besar dan luas menjadi lebih mudah untuk direncanakan dan dikerjakan. Tim harus mereka yang sudah melek media sosial dan dilatih untuk membuat konten-konten yang sesuai dengan tujuan misi dengan memperhatikan etika dalam bermedia sosial. Tim yang dimaksud bukan hanya sesama orang yang melakukan misi tetapi lebih daripada itu menjadi satu tim dengan Roh Kudus yang bekerja di dalam hati setiap orang.

\section{Implikasi}

Implikasi dari penelitian ini, secara teoritis dapat menambah kajian literatur untuk penelitian misi jangka pendek dan misi di media sosial bagi mahasiswa sekolah teologi di Indonesia, sebab masih sedikit penelitian-penelitian seperti itu. Dan secara praktis, penelitian ini dapat memaksimalkan implementasi strategi misi jangka pendek dan misi di media sosial.

\section{Rekomendasi untuk Penelitian Lanjutan}

Penelitian selanjutnya bisa meneliti peran dosen pembimbing dalam misi jangka pendek, dan usaha pemuridan kepada orang-orang yang sudah dilayani

${ }^{45}$ Yosua Feliciano Camerling, Mershy Ch. Lauled, and Sarah Citra Eunike, “Gereja Bermisi Melalui Media Digital Di Era Revolusi Industri 4.0," Visio Dei: Jurnal Teologi Kristen 2, no. 1 (2020): 122. 14-19.

${ }^{46}$ Artahsasta Meylano, Misi Apologetika Kristen Online Di Aplikasi Discrod Pada Komunitas Server Among Us Indonesia (Toraja, 2020), 9. https:/ / osf.io/q2m7b.

${ }^{47}$ Sri Wiranti Setiyanti, “Membangun Kerjasama Tim (Kelompok)," Jurnal STIE Semarang 4, no. 3 (2012): 65 . 
dalam misi jangka pendek, sebab menurut hasil penelitian Bilangan Research masih banyak orang yang sudah dilayani di Indonesia tapi minim pemuridan. ${ }^{48}$

\section{Kesimpulan}

Berdasarkan uraian dari tulisan ini maka penulis menyimpulkan beberapa hal di bawah ini: pertama, strategi misi mahasiswa sekolah teologi dalam konteks budaya di Indonesia perlu memperhatikan budaya yang ada. Seperti yang sudah dilakukan oleh para misionaris ketika mereka datang ke Indonesia. Mereka belajar bahasa, adat atau budaya untuk bisa berkomunikasi dengan kelompok orang sebelum mereka menyampaikan Injil. Hal ini membutuhkan waktu yang cukup lama dan membutuhkan biaya yang besar. Sebab itu misi yang perlu dilakukan oleh misionaris lokal atau mahasiswa sekolah teologi ketika mereka sudah dilatih untuk melakukan misi penjangkauan, yaitu misi "pulang kampung." Menjangkau kelompok orang yang belum terjangkau melalui misi kemanusiaan, misi sosial, dan misi spiritual. Hal ini dilakukan sebagai misi jangka pendek (sort-term mission). Kedua, strategi misi mahasiswa sekolah teologi dalam konteks kemajuan teknologi yaitu melalui misi di media sosial. Hal ini bisa dilakukan dengan menggunakan berbagai platform yang banyak digunakan oleh masyarakat Indonesia seperti Youtube, Facebook, Instagram, Whatsaap dan Twitter. Untuk melakukan hal-hal tersebut dibutuhkan kemitraan dan tim yang solid. Ketiga, strategi misi yang dilakukan harus dilakukan dalam kebergantungan kepada Roh Kudus, sebab tanpa Roh Kudus maka semua strategi misi akan menjadi sia-sia. Setiap misionari atau mahasiswa sekolah teologi perlu menjadi satu tim dengan Roh Kudus yang akan bekerja di dalam hati setiap orang untuk memampukan mereka mengerjakan pekerjaan-pekerjaan Allah.

\section{Rujukan}

Ver Beek, Kurt Alan. “The Impact of Short-Term Missions: A Case Study of House Construction in Honduras after Hurricane Mitch." Missiology: An International Review 34, no. 4 (2006): 477-495.

Beyerlein, Kraig, Jenny Trinitapoli, and Gary Adler. “The Effect of Religious ShortTerm Mission Trips on Youth Civic Engagement." Journal for the Scientific Study of Religion 50, no. 4 (2011): 780-795.

Bilangan Research. "Spiritualitas Umat Kristen Indonesia," no. April (2021). Brake, Andrew. Menjalankan Misi Bersama Yesus: Pesan-Pesan Bagi Gereja Dari Kisah Para Rasul. Bandung: Kalam Hidup, 2016.

Camerling, Yosua Feliciano, Mershy Ch. Lauled, and Sarah Citra Eunike. “Gereja Bermisi Melalui Media Digital Di Era Revolusi Industri 4.0." Visio Dei: Jurnal Teologi Kristen 2, no. 1 (2020): 1-22.

Creswell, John W. Research Design: Qualitative, Quantitative, and Mixed Methods Approaches. Thousand Oaks: Sage Publication, Inc, 2009.

Farrell, B Hunter. "From Short-Term Mission to Global Discipleship : A Peruvian Case Study." Missiology: An International Review 4, no. 2 (2013): 163-178. Harming, H, and K Katarina. "Strategi Pelayanan Lintas Budaya Berdasarkan

\footnotetext{
48 Bilangan Research, “Spiritualitas Umat Kristen Indonesia,” no. April (2021). 211.
} 
Markus 4:1-34." Evangelikal: Jurnal Teologi Injili dan Pembinaan Warga Jemaat 3, no. 1 (2019): 113.

Hesselgrave, David J. Communicating Christ Cross-Culturally. Edisi Kedu. Malang: Literatur SAAT, 2005.

KBBI. “Kamus Besar Bahasa Indonesia.” Kbbi.Web.Id. Last modified 2021. https:/ / kbbi.kemdikbud.go.id/entri/Pulang kampung.

Kominfo. "Media Sosial," n.d.

Lingenfelter, Sherwood G., and Marvin K. Mayers. Menggeluti Misi Lintas-Budaya: Meniru Kristus Mengatasi Perbedaan. Jakarta: Yayasan Komunikasi Bina Kasih, 2008.

Linhart, Terence D. "Planting Seeds : The Curricular Hope of Short Term Mission Experiences in Youth Ministry." Christian Education Journal 2, no. 2 (2005): 256272.

Meylano, Artahsasta. Misi Apologetika Kristen Online Di Aplikasi Discrod Pada Komunitas Server Among Us Indonesia. Toraja, 2020. https:/ /osf.io/q2m7b.

Mulyana, Deddy. Komunikasi Efektif: Suatu Pendekatan Lintas Budaya. Bandung: PT. Remaja Rosdakarya, 2005.

Nainggolan, Bartholomeus Diaz. “Interpretation of Acts 1:8 and Its Implementation in Cross-Cultural Gospel Mission." Jurnal Koinonia 10, no. 2 (2018): 16-18.

Panjaitan, Firman, and Hendro Siburian. "Misi Kristologi Dalam Konteks Kebudayaan." Logia: Jurnal Teologi Pentakosta 1, no. 1 (2020): 42-59.

Pasaribu, Ria. Komunitas Yang Bermitra Dalam Misi. Jakarta: Yayasan Komunikasi Bina Kasih, 2011.

Penulis. Wawancara Dengan Andrew Suplig, M.Th Sebagai Dosen Pembimbing Tim Misi Ke Ampana. Makassar, 2021.

- - - . Wawancara Dengan Jeanet Memah Seorang Mahasiswa Peserta Mission Trip Ke Ampana. Makassar, 2021.

Piper, John. Jadikan Sekalian Bangsa Bersukacita: Supremasi Allah Dalam Misi. Edited by Doreen Widjaya. Bandung: Lembaga Literatur Baptis, 2003.

Priest, Robert J, and Joseph Paul Priest. "'They See Everything, and Understand Nothing' Short-Term Mission and Service Learning." Missiology: An International Review XXXVI, no. I (2008): 53-73.

- - - ." They See Everything, and Understand Nothing' Short-Term Mission and Service Learning." Missiology: An International Review XXXVI, no. 1 (2008): 5373.

Schultze, Quentin J. Communicating for Life: Christian Stewardship in Community and Media. Malang: Literatur SAAT, 2004.

Setiyanti, Sri Wiranti. “Membangun Kerjasama Tim (Kelompok).” Jurnal STIE Semarang 4, no. 3 (2012): 65.

Smith, Donald K. Creating Understanding: Buku Panduan Komunikasi Kristen Lintas Budaya. Jogyakarta: Penerbit ANDI, 2014.

Tenibemas, Purnawan. “Andil Kita Dalam Misi Masa Kini." Pengarah: Jurnal Teologi Kristen 1, no. 1 (2019): 23-36.

"Hasil Sensus Penduduk Tahun 2020." Badan Pusat Statistik. Last modified 2021. Accessed June 13, 2021. https:/ / www.bps.go.id/. 
"Kelompok Orang: Indonesia." The Joshua Project. Last modified 2021. Accessed June 13, 2021. joshuaproject.net.

"KKBI Daring." Kemendikbud. Last modified 2016. https:/ / kbbi.kemdikbud.go.id/entri/korupsi.

Kominfo: Survey Penggunaan TIK Serta Implikasinya Terhadap Aspek Sosial Budaya Masyarakat. Jakarta, 2017.

“Laporan Misi," 2020.

“Pengguna Media Sosial.” Databoks. Last modified 2021. Accessed June 16, 2021. https:/ / databoks.katadata.co.id/tags/pengguna-media-sosial.

"Serving in Mission (SIM)." Last modified 2021. Accessed June 12, 2021. https:/ / sim.org.nz/.

"Share It." EE Center Indonesia. Last modified 2021. Accessed June 15, 2021. https:/ / eeindonesia.org/.

“The Christian Missionary Alliance (CMA).” Last modified 2021. Accessed June 12, 2021. https:/ / cmalliance.org/about/.

"Youth With A Mission." Last modified 2021. Accessed June 12, 2021. https://ywam.org/. 